\title{
PELATIHAN APLIKASI PENGGUNAAN MATLAB UNTUK MENINGKATKAN PENGETAHUAN GURU
}

\section{Training Applications In The Use of Matlab to Improve Teacher Knowledge}

\author{
Ahmad Yanie' \\ Lisa Adriana Srg ${ }^{2}$ \\ Junaidi ${ }^{3}$ \\ $*_{1,2,3}$ Universitas Harapan Medan \\ *email: \\ yani.ahmad34@yahoo.com
}

\begin{abstract}
Abstrak
Dewasa ini tugas guru dirasakan sangat semakin berat dengan bergantinya kurikulum yang digunakan, yaitu menjadi Kurikulum Berbasis Kompetensi (KBK) dengan salah satu metode pembelajaran yang ada yaitu pembelajaran Contextual Teaching Learning (CTL). Suatu pembelajaran dengan menggunakan alat bantu komputer menjadi satu syarat yang penting dalam pembelajaran dengan sistem CTL tersebut, sehingga menjadi suatu keharusan bagi guru untuk dapat menguasai software-software komputer yang dapat membantu suatu pembelajaran. Software yang dapat membantu pembelajaran matematika di kelas adalah software MATLAB atau Matrix Laboratory yang dewasa ini banyak telah dimanfaatkan oleh pengajar pada mata pelajaran matematika dan kejuruan Teknik. Untuk meningkatkan kemampuan guru dalam memanfaatkan komputer dalam pembelajaran terutama pada penggunaan software MATLAB, maka diadakanlah "Pelatihan Aplikasi Penggunaan Matlab Untuk Meningkatkan Pengetahuan Guru “.
\end{abstract}

Kata Kunci:

Pelatihan

Aplikasi

Komputer

Matlab

Keywords:

Training

Application

Computer

Matlab

\begin{abstract}
Nowadays the task of the teacher is felt to be getting tougher with the change in the curriculum used, which is to become a Competency Based Curriculum (CBC) with one of the existing learning methods namely Contextual Teaching Learning (CTL) learning. $A$ learning using computer aids becomes an important requirement in learning with the CTL system, so it becomes a necessity for teachers to be able to master computer software that can help a learning. Software that can help learning mathematics in the classroom is MATLAB or Matrix Laboratory software, which is currently being used by teachers in mathematics and vocational engineering. To improve the ability of teachers to utilize computers in learning, especially in the use of MATLAB software, a "Training on the Use of Matlab Applications to Increase Teacher Knowledge" was held.
\end{abstract}




\section{PENDAHULUAN}

Pemanfaatan TIK sudah menyentuh hampir seluruh aspek kehidupan masyarakat. Termasuk salah satunya dalam mendukung pengelolaan sekolah. Rencana Strategis Departemen Pendidikan Nasional, secara eksplisit menyebutkan tiga pilar kebijakan pendidikan nasional, yaitu: (I) perluasan dan pemerataan akses, (2) peningkatan mutu, relevansi dan daya saing, dan (3) penguatan tata kelola, akuntabilitas dan citra publik pendidikan, untuk mewujudkan pendidikan yang bermutu, murah, merata dan trjangkau rakyat banyak. Peran strategis TIK yaitu perluasan dan pemerataan akses pendidikan, di prioritaskan sebagai peningkatan mutu, relevansi dan daya saing. Peran TIK diprioritaskan untuk penerapan dalam pendidikan/ proses pembelajaran.

Namun pemanfaatan ini belum merata di seluruh tingkat pendidikan. Kendala penerapan TIK antara lain kurangnya keterampilan guru dalam menggunakan aplikasi komputer seperti Aplikasi Program Matlab. Hal ini yang mendasari adanya pengabdian kepada masyarakat, khususnya para guru dan peserta didik di Sekolah MTs Al-Itihadiyah di Kecamatan Medan Johor. Dalam kerangka itu, maka menjadi kewajiban bagi Dosen untuk melaksanakan Tridharma Perguruan Tinggi, yaitu melaksanakan Pendidikan, Penelitian, dan Pengabdian. Dalam rangka pemenuhan Tridharma Perguruan Tinggi tersebut, berbagai macam bentuk pengabdian terhadap sesama masyarakat hendaknya dapat dilakukan oleh para Dosen.

Salah satu program pengabdian yang dilakukan adalah dalam bentuk bakti sosial. Bakti sosial ini merupakan wadah pembekalan dosen untuk menyalurkan minat dan bakatnya dalam mengamalkan profesionalisme disiplin ilmu ke tengah masyarakat. Manfaat lain dari bakti sosial ini adalah menciptakan rasa Kepekaan terhadap sesama yang membutuhkan. Kegiatan Pengabdian Masyarakat ini yang berjudul "Pelatihan Aplikasi Penggunaan Matlab untuk meningkatkan pengetahuan Guru Matematika" pada Sekolah MTs Al-Itihadiyah di Kecamatan Medan Johor. Pengabdian ini diselenggarakan oleh Dosen Universitas Harapan Medan .

Tentunya Kegiatan Pengabdian ini memerlukan dukungan dan bantuan dari berbagai pihak, baik sivitas akademika Universitas Harapan Medan maupun pihak lain atas dasar kebersamaan. Dukungan moral dan materi akan sangat membantu program ini, yang dengan semangat kemanusiaan dan pengabdian masyarakat mampu menolong mereka yang membutuhkan.

\section{METODOLOGI}

Sasaran dalam kegiatan pengabdian masyarakat ini adalah guru-guru Sekolah di MTs Al-ltihadiyah Medan Johor. Terdapat sebanyak tiga puluh empat orang guru sekolah di MTs Al-Itihadiyah tersebut yang dipimpin oleh Kepala Sekolah Pamonaran Siregar,Mpdi. Pada sekolah MTs Al-ltihadiyah tersebut terdapat dua puluh ruang kelas, yang terdiri dari tujuh ruang kelas VII, tujuh ruang kelas VIII. Seluruh murid berjumlah 734 siswa dan tiap kelas berjumlah 36 siswa. Selama diadakan diskusi bersama antara guru-guru dan kepala sekolah, mereka sangat antusias denagn akan diadakannya suatu pelatihan Teknologi Komputer dalam hal ini penggunaan aplikasi Matlab dalam meningkatkan mutu pembelajaran.

Para guru sangat senang dan mengucapkan terima kasih kepada kepala sekolah Pamonaran Siregar, selama kepemimpinannya selalu memberikan perhatian dan dukungan. la berharap semoga kedepannya dapat memberikan perhatian yang lebih lagi pada peningkatan pengetahuan Guru-guru dalam bidang Teknologi Komputer.

Kepala Sekolah MTs Al-ltihadiyah Pamonaran Siregar, Mpdi didalam sambutannya yang dibacakannya menyampaikan bahwa Pendidikan baik formal maupun non formal sangat membantu dalam mencerdaskan anak bangsa yang merupakan asset bangsa dan investasi 
pembangunan dimasa depan. Dirinya berharap agar para pendidik juga harus memiliki SDM yang memadai agar dapat menjadikan anak-anak didik menjadi anakanak yang berkualitas. Sesuai tema yang diusung "Mari kita satukan pemikiran yang kreatif dan inovatif untuk menjadikan generasi yang berakhlak mulia”.

\section{Metode Pelaksanaan}

Untuk metode pelaksanaan kegiatan pelatihan sendiri ada beberapa hal hal yang perlu dilakukan diantaranya adalah sebagai berikut:

I. Melakukan pendataan peserta pelatihan pada Guruguru Sekolah MTs Al-Itihadiyah di Kecamatan Medan Johor yang ditempat acara untuk didata identitasnya laki-laki atau perempuan.

2. Dilakukan pemaparan materi oleh tim Dosen dilanjutkan dengan istirahat sambil ramah-tamah dengan peserta pelatihan pada Sekolah MTs AlItihadiyah di Kecamatan Medan Johor.

\section{Tujuan Kegiatan}

Adapun tujuan dari pengabdian masyarakat bagi Guru-guru disekolah MTs Al-Itihadiyah Kecamatan Medan Johor ini adalah:

I. Memberikan pelatihan dasar tentang Aplikasi Program Matlab

2. Memberikan konstribusi terhadap pendidikan sebagai bentuk pengabdian kepada masyarakat bagi dosen yang menjalankan tugas Tri Dharma Perguruan Tinggi.

\section{Manfaat Kegiatan}

Adapun manfaat yang diharapkan dalam pengabdian masyarakat bagi Guru-Guru di Sekolah MTs Al-Itihadiyah Kecamatan Medan Johor ini adalah:

I. Meningkatkan kepekaan sosial Dosen Universitas Harapan Medan,

2. Sebagai wadah pengamalan ilmu dan pembelajaran,
3. Mengamalkan pengetahuan dan keterampilan Dosen Universitas Harapan Medan,

4. Mempererat tali persaudaraan masyarakat (Guru) dengan para Dosen UniversitasHarapan Medan.

\section{HASIL DAN PEMBAHASAN}

Keberhasilan pelaksanaan program pengabdian masyarakat ini dapat dilihat dari dua tolok ukur sebagai berikut:

a) Respons positif dari peserta pelatihan.

Respons peserta pelatihan akan diukur melalui observasi selama pelatihan berlangsung dan dengan mengadakan diskusi yang menyangkut kesan, saran, kritik dan usulan peserta pelatihan terhadap program pengabdian masyarakat ini.

b) Meningkatnya keterampilan peserta setelah mendapat pelatihan. Keterampilan peserta akan di observasi saat pelatihan melalui tugas-tugas tentang contoh aplikasi Program Matlab.

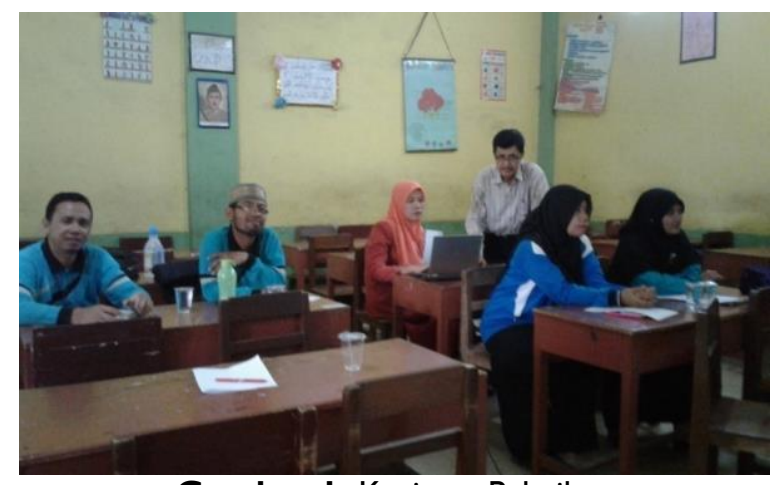

Gambar I. Kegiatan Pelatihan

\section{Pembahasan}

Dengan Matlab, persamaan matematika dan aljabar dapat diselesaikan dengan mudah, dibandingkan dengan menggunakan rumus-rumus umum. Programnya lebih singkat, hasilnya lebih cepat dan menarik serta interaktif.

Berikut contoh dari penggunaan program Matlab.

Contoh I. Membuat vector dan matriks.

Untuk membuat matriks dalam Matlab, yaitu:

Dari promt: $>A=\left[\begin{array}{lllllll}1 & 2 & 3 ; 4 & 5 & 6 ; 7 & 8 & 9\end{array}\right] \leftarrow$

$A=$ 


$$
\begin{array}{lll}
4 & 5 & 6 \\
7 & 8 & 9
\end{array}
$$

Contoh 2: Adalah cara untuk membuat Grafik tanpa grid dan menggunakan grid

$>\mathrm{t}=\left[\begin{array}{llllllll}1 & 0 & 3 & 4 & 2 & 1 & 5 & 4\end{array}\right.$;

68371262 ;

9 I 454326 ;

4942 । 93 7];

$>>\operatorname{bar}(\mathrm{t}) \leftarrow$

$>$ grid on

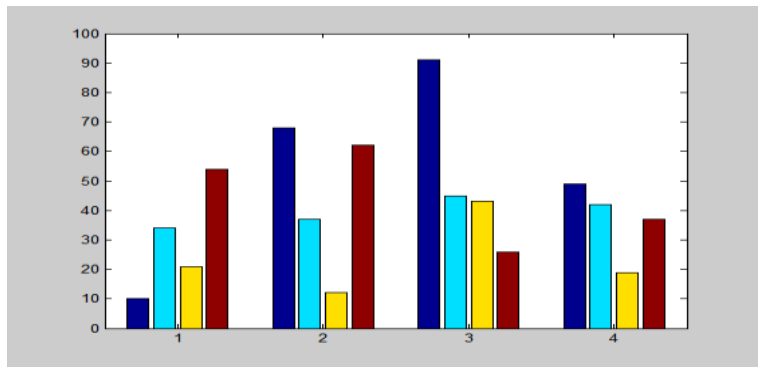

Gambar 2. Grafik tanpa grid

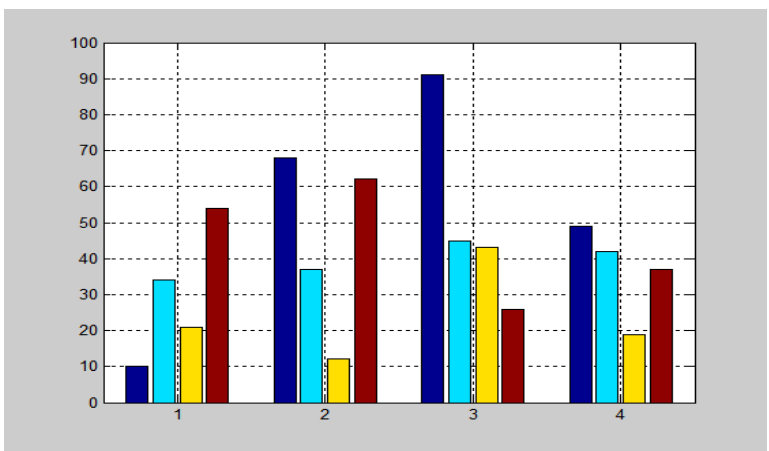

Gambar 3. Grafik menggunakan grid

\section{KESIMPULAN}

Dari hasil evaluasi serta temuan-temuan yang kami peroleh selama pelaksanaan kegiatan pengabdian masyarakat ini, dapat kami simpulkan bahwa program pengabdian masyarakat sebagai salah satu wujud dari pelaksanaan Tri Dharma Perguruan Tinggi ini telah mampu memberikan manfaat bagi khalayak guru-guru sekolah MTs Al-Itihadiyah di Kecamatan Medan Johor yang menjadi sasaran pengabdian ini. Bentuk pelatihan seperti ini merupakan bentuk yang effektif untuk memberikan penyegaran dan wawasan baru dibidang teknologi informasi di luar proses pembelajaran yang diterima diluar pelatihan ini, dan dalam pelaksanaan Program Tri Dharma Perguruan Tinggi ini, yaitu pelatihan aplikasi program matlab pada guru-guru sekolah MTs Al-ltihadiyah tidak ada kendala yang menghambat selama proses pelatihan.

\section{SARAN}

Sesuai dengan hasil evaluasi respons yang telah dilakukan, kami menyarankan hendaknya programprogram pengabdian masyarakat seperti ini dilaksanakan secara regular dan berkala, melihat tingkat kebutuhan yang tinggi akan pengenalan aplikasiaplikasi komputer yang baru, dalam jangka waktu yang relatif singkat megikuti perkembangan teknologi secara global.

\section{REFERENSI}

Ahmad Yanie, J. (2016). Pelatihan Aplikasi Penggunaan matlab untuk meningkatkan Pengetahuan Guru Mate Matika.

Aris Sugiharto, Pemrograman GUI dengan MATLAB, ANDI, Yogyakarta,2006

Junaidi, Jumadi, Mhd.Akhir, Mhd.Idris, Haida, jamiah, darmawati, S. nst. (20I5). Pelatihan Penilaian Prestasi Kerja Terhadap Promosi Pegawai Pada Kantor Kepala Desa Mata Pao Kecamatan Teluk Mengkudu Kabupaten Serdang Bedagai. In Laporan PenGABDIAN (p. 35). P4M STTH.

K.A. Stround, Dexter J. Boot (2003). Matematika Teknik. 5ed,Penerbit Erlangga.

Lukman Hakim Siregar I, L. D., \& Junaidi2, S. (2020). Pelatihan Perencanan Bisnis Jasa Sewa Kapal Motor "Mancing Mania" Di Kelurahan Nelayan Indah Kecamatan Medan Labuhan Kota Medan. Reswara: Jurnal Pengabdian Kepada Masyarakat, I(I), 24-33.

Siswati Saragil, K., Sinaga2, Budiman Purba3, M., \& Batoebara4, U. (2020). Pelatihan Peracikan Kopi Untuk Meningkatkan Minat Wirausaha Masyarakat Desa Rugemuk Kabupaten Deli Serdang. RESWARA: Jurnal Pengabdian Kepada Masyarakat, I(I), 34-37.

Umar Hamdan Nasution I, E., \& Iskandar2, C. Z. (2020). Pkm Pelatihan Perencanaan Bisnis Makanan Khas Laut Di Kelurahan Nelayan Indah. RESWARA: Jurnal Pengabdian Kepada Masyarakat, I(I).

Wijaya Widjanarka.N. (2006). Teknik Digital, Penerbit Erlangga Jakarta. 